\section{Cahiers d'ethnomusicologie}

Anciennement Cahiers de musiques traditionnelles

$10 \mid 1997$

Rythmes

\title{
Inde. Tabla solo. Hommage à Latif Ahmed Khan
}

Archives internationales de musique populaire, Musée d'ethnographie de Genève, 1996

\section{Martin Clayton}

\section{(2) OpenEdition}

\section{Journals}

Édition électronique

URL : http://journals.openedition.org/ethnomusicologie/937

ISSN : 2235-7688

\section{Éditeur}

ADEM - Ateliers d'ethnomusicologie

\section{Édition imprimée}

Date de publication : 1 décembre 1997

Pagination : 345-346

ISBN : 2-8257-0579-9

ISSN : $1662-372 X$

\section{Référence électronique}

Martin Clayton, «Inde. Tabla solo. Hommage à Latif Ahmed Khan », Cahiers d'ethnomusicologie [En ligne] 10 | 1997, mis en ligne le 06 janvier 2012, consulté le 19 avril 2019. URL : http:// journals.openedition.org/ethnomusicologie/937

Ce document a été généré automatiquement le 19 avril 2019.

Tous droits réservés 


\section{Inde. Tabla solo. Hommage à Latif Ahmed Khan}

Archives internationales de musique populaire, Musée d'ethnographie de Genève, 1996

\section{Martin Clayton}

\section{RÉFÉRENCE}

Inde. Tabla solo. Hommage à Latif Ahmed Khan. Enregistrements : Paul Meyer, Jean-Luc Meylan (1976-77). Texte de présentation : Bruno Caillat. CD VDE-Gallo 909, Archives internationales de musique populaire, Musée d'ethnographie de Genève, AIMP XLV, 1996.

1 Ce CD, qui contient des enregistrements en studio et en concert du tabliste Latif Ahmed Khan réalisés en Suisse en 1976 et en 1977, est particulièrement bienvenu. Latif Ahmed, qui mourut en 1989 à l'âge de quarante-sept ans, était un interprète doué et très respecté, même si son jeu pouvait parfois être assez singulier. Actif à une époque où le solo de tablā commençait à trouver une place largement méritée sur la scène internationale, Latif Ahmed fut l'un des artistes qui contribuèrent à lui donner ses lettres de noblesse. C'était un musicien accompli, aussi bien soliste qu'accompagnateur, et il jouissait d'une grande popularité en Inde et en Europe. Son art mérite bien d'être remémoré grâce à une telle publication.

2 Le disque comporte six pièces. La première est une présentation très ample du vilambit tìntāl (lent), morceau de base du répertoire de tablā. Dans la seconde, Latif Ahmed nous régale d'un cautāl à douze temps, d'habitude joué sur le tambour cylindrique pakhāvaj dont le son est ici imité au tablā « grave » accordé au cinquième degré de la gamme ( $\mathrm{Pa})$. A l'heure actuelle, c'est une pratique courante; mais ce qui suit ne l'est pas, car le soliste passe d'un cautāl à un drut tīntāl (rapide) au cours duquel il joue un passage en savāl-javāb (question - réponse) qui fait alterner le tabla normal et le grave.

3 Après le rūpak tāl et le drut tīntāl qui composent les quatrième et cinquième plages du disque, on découvre l'une des inventions particulières de Latif Ahmed, baptisée « Latiftāl » 
et mentionnée ici comme étant à cinq temps et quart. En réalité, ce tâl est construit en trois parties, chacune d'une durée de la moitié de la précédente : $3+1^{1} /{ }^{2}+3 / 4$ de temps. Le $\mathrm{CD}$ se termine sur une pièce en dādrā tāl dont la caractéristique principale est la présence de l'accompagnateur Asif Ali Khan au sārangĩ. La sonorité de ce dernier est exactement celle des joueurs de sārangi populaires du Rajasthan, ce qui se justifie tout à fait dans un tel contexte.

Ces enregistrements sont de qualité inégale, les imperfections les plus manifestes se trouvent au début du cautāl et au dādrā qui est gâché par un écho tonitruant. La notice reconnaît toutefois ces défauts et, admettons-le, ce n'est pas cher payer pour avoir accès à de si précieux enregistrements.

La documentation est excellente et comporte des notes en français et en anglais rédigées par Bruno Caillat, élève de Latif Ahmed. Il s'agit là d'un élément essentiel sans lequel la construction des solos de tablā demeurerait impénétrable même pour la plupart des amateurs de musique savante de l'Inde du Nord. Les notes de Caillat, bien qu'elles risquent de ne pas être à la portée du débutant, seront précieuses pour tout auditeur ayant assimilé les notions de base du tāl de l'Inde du Nord, mais devant encore être guidé pour pouvoir suivre l'organisation formelle d'un solo de tablā. Plusieurs études de premier plan sur le répertoire de tabla ont été publiées ces dernières années, en particulier celles de Stewart, Gottlieb et Kippen; les enregistrements de solos de tablā sont de plus en plus fréquents et certains des interprètes sont devenus des vedettes mais tout document qui met en rapport des sons enregistrés avec la théorie sera toujours bienvenu. Les notes comportent aussi une biographie du soliste ainsi qu'une brève introduction au tablā et au système du tāl.

Tout en nous réjouissant de trouver une telle documentation, nous mentionnerons une ou deux petites erreurs: le tablā "grave » dans le cautal est accordé à une quarte en dessous de la hauteur du tablā standard, et non à une octave comme le suggère l'auteur; et certaines des traductions "littérales" de termes techniques sont inexactes. Par exemple paran, le nom d'une catégorie de compositions pour pakhavāj dont l'origine est incertaine, est transcrit parhan, qui veut dire récitation : un rapport étymologique est possible mais les mots sont différents. Il faut dire à la décharge de l'auteur que ce genre d'interprétation est souvent incertaine et que les musiciens eux-mêmes ont souvent recours à des étymologies incorrectes pour expliquer des termes musicaux.

7 Il y a donc ici, pour résumer, de quoi divertir et instruire toute personne ayant un goût pour le tablā et pour les merveilles rythmiques de l'Inde du Nord.

\section{BIBLIOGRAPHIE}

GOTTLIEB Robert S., 1977, The major traditions of North Indian tabla drumming. Band 1. MünchenSalzburg : NGOMA.

KIPPEN James R., 1988, The tabla of Lucknow : a cultural analysis of a musical tradition. Cambridge : Cambridge U.P. 
STEWART R.P., 1974, The tabla in perspective. Ph.D. dissertation. Los Angeles : U.C.L.A. 